\title{
Quantitative Perspectives on Deconverts and Traditionalists Revisited
}

\section{Heinz Streib and Barbara Keller}

The main part of this book consists of case studies that are based on repeated faith development interviews (FDI) and their evaluation using methods such as content analysis and narrative analysis. But the case studies also take into account perspectives on religious development resulting from the structural evaluation of the FDIs (Fowler, 1981; Streib \& Keller, 2018). And not at least, the case studies consider also the quantitative profile of the re-interviewees as reflected in their questionnaire answers at both times of interviewing. This chapter aims at quantitatively profiling the sample of re-interviewees in order to enrich the case studies that are presented in later chapters of this book.

\section{Research Questions and Assumptions}

The distinction between deconverts and traditionalists (previously called "in-tradition members") has been central from the beginning of our deconversion research (Streib, Hood, Keller, Csöff, \& Silver, 2009). ${ }^{1}$ In our original study, the deconverts received special attention; therefore, we started with the search for deconverts who were ready to participate in our study, and then we aimed at finding members of the specific religious tradition, from which the deconvert had distanced themselves, who also agreed to participate in the questionnaire and part of them agreed to a personal interview. As a result, there are FDI evaluations from 179 traditionalists and 93 deconverts in the data base from the first Deconversion Study.

Now in this second wave, we could locate and re-interview 21 deconverts and 24 participants, who in the first wave were identified as traditionalists. But the biographical and religious trajectories of participants did not end with the completion of the original Deconversion Study. On the contrary, they have, in the time between the first and the second participation in our studies, experienced conversions, deconversions, and other migrations in the religious field. Therefore, it is inappropriate to fix them to their role as traditionalists and deconverts more than ten years ago. Of special interest are deconversions of former traditionalists that occurred in the past ten years. Because we have asked in our second-wave questionnaire for detailed information about recent deconversions, 8 of the 24 Time 1 traditionalists report at Time 2 that they have deconverted in the meantime. Therefore, we have in our sample 29 (64.5\%)

\footnotetext{
${ }^{1}$ Note on terminology: As explained in previous publications (Paloutzian, Murken, Streib, \& Namini, 2013; Streib, 2014; Streib et al., 2009; Streib \& Keller, 2004), people who distanced and eventually disaffiliated from their religious tradition were called "deconverts," while participants who stayed in their tradition were called "intradition members”; the latter are labeled now "traditionalists.” Traditionalists are considered followers and stable affiliates of a certain religious tradition, while deconverts are seekers, who consider other religious traditions or no religious tradition and eventually disaffiliate.
} 
participants who report one or multiple deconversions in their past. For our analyses, we will therefore use the three groups:

(1) Traditionalists, who reported at Time 1 and/or Time 2 that they "never have left a religious tradition or worldview tradition," thus report no deconversion;

(2) Time 1 deconverts, who reported deconversion at Time 1 (and repeated their report about a deconversion in the questionnaire at Time 2); and

(3) Time 2 deconverts, who reported in the questionnaire at Time 2 a deconversion between Time 1 and time 2.

We assume clear differences between these three groups at Time 2. Such group differences are assumed for religious development, spiritual/religious self-identification, personality factors, and well-being. Thereby, the assumptions for the second-wave analyses relate to the results from the first Deconversion Study (Streib et al., 2009).

Religious development has been assessed using the structural evaluation of the FDIs based on the 3rd edition of the Coding Manual (Fowler, Streib, \& Keller, 2004). It has been one of the remarkable results reported in the first Deconversion Study (Streib et al., 2009, for example, in Figure 4 on p. 102) that, compared to traditionalists, religious development of deconverts is more advanced. This conclusion could be drawn from the result that the individuative-reflective style (Style 4) was found in a considerably higher percentage of FDIs with deconverts: ca. 50\% of the FDIs with deconverts in both the US and the German sample were rated individuativereflective (Style 4), while only less than $10 \%$ of the traditionalists' FDIs in the US sample and about $25 \%$ in the German sample were rated individuative-reflective. Therefore, we assume that also in the second-wave FDI results, deconverts show a considerably higher preference for the individuative-reflective style and thus corroborate findings from the first wave that deconverts are developmentally more advanced.

In regard to spiritual/religious self-identification, the first Deconversion Study has revealed that the number of self-identified "more spiritual than religious" deconverts almost doubles the amount of self-identified "more spiritual than religious" traditionalists, and we concluded "in both cultures, the United States and Germany, deconversion is associated with a reluctance to identify with 'being religious' and a strong preference to self-identify as being 'more spiritual than religious' or, to a lesser degree, as being 'neither religious nor spiritual'” (Streib et al., 2009, p. 87). Therefore, we assume that also in the second-wave FDI results, deconverts identify as being "more spiritual than religious" to a higher degree.

The three subscales of the Religious Schema Scale (Streib, Hood, \& Klein, 2010) have accounted for the difference between traditionalists and deconverts at Time 1, with cultural differences between the US and the German samples. While all three RSS subscales, truth of text and teachings (ttt), fairness, tolerance and rational choice (ftr), and xenosophia/interreligious dialog (xenos) have differentiated between traditionalists and deconverts in the US sample, for the German participants, only the difference in ttt reached significance (Streib et al., 2009, p. 74). We can conclude that Time 1 deconverts in both countries are much more reluctant to agree to the truth of their religious tradition than traditionalists. The research question is whether this difference has stability over the time between the first and second time of interviewing, and whether Time 2 deconverts will have lower $t t$ scores after they have deconverted between Time 1 and 2. Our expectation is an affirmative answer to both questions. 
From the "big five" personality factors, which were measured with the NEO-FFI (Costa \& McCrae, 1985), openness to experience was the variable that indicated the largest differences between deconverts and traditionalists in both the US and German sample, while lower emotional stability (neuroticism reversed), agreeableness, and conscientiousness was indicated for the German deconverts only (Streib et al., 2009, p. 74-79). Thus we may conclude from these Time 1 results with the assumption that scores on openness to experience will also differ between the traditionalists and deconverts in both Germany and the US at Time 2, while emotional stability, agreeableness, and conscientiousness may be lower at Time 2 for German deconverts only.

Well-being has been assessed with the Psychological Well-Being and Growth Scale (Ryff, 1989; Ryff \& Singer, 1998) at both times of measurement. Results at Time 1 revealed lower scores on environmental mastery, positive relations with others, purpose in life, and selfacceptance for the German deconverts - which we have interpreted as "signs of a loss or a crisis" (Streib et al., 2009, p. 81). These findings give raise to the question whether this loss or crisis continued over the time distance of ten years or whether these German deconverts have experienced some improvement in the meantime. For new Time 2 deconverts in Germany, we may expect that their scores on environmental mastery, positive relations with others, purpose in life, and self-acceptance indicate a similar loss and crisis as revealed for the Time 1 deconverts ten years ago.

\section{Participants}

Participants from the original Deconversion Study sample (Streib et al., 2009) were, after ca. ten years, invited to fill out our questionnaire for a second time and participate in a second faith development interview. The resulting questionnaire sample consists of $N=49$ participants, including $N=39$ participants who also completed a re-interview with the FDI. In addition, there were $N=6$ FDI re-interviewees who did not participate in the questionnaire, but may be important for qualitative analysis; they were included in the FDI sample resulting in a total of $N=45$ FDI re-interviewees. Even though both samples overlap, basic demographics are presented separately (see Table 1). 
Table 1. Basic Demographics for Participants with Questionnaire Data and FDI Evaluation at Time 1 and Time 2

\begin{tabular}{|c|c|c|}
\hline & $\begin{array}{l}\text { Questionnaire } \\
\text { Sample }\end{array}$ & FDI Sample \\
\hline$N$ & 49 & 45 \\
\hline Gender: \% female & $44.9 \%$ & $51.1 \%$ \\
\hline Mean age [age range] at Time 2 (Time 1 ) & $\begin{array}{r}56.3[34-82] \\
(45.3[23-71])\end{array}$ & $\begin{array}{r}56.7[34-82] \\
(43.7[16-71])\end{array}$ \\
\hline Country: \% Germany & $93.9 \%$ & $82.2 \%$ \\
\hline $\begin{array}{l}\text { Cultural Capital: \% tertiary education at Time } 2 \\
\text { (Time 1) }\end{array}$ & $65.3 \%(61.2 \%)$ & $67.6 \%(58.5 \%)$ \\
\hline Per-capita Income Mean at Time $2(S D)$ & $\$ 45,147(\$ 26,939)$ & $\begin{array}{r}\$ 46,291 \\
(\$ 27,117)\end{array}$ \\
\hline \multicolumn{3}{|l|}{$\begin{array}{l}\text { Religious Affiliation, \% in major groups, at Time } 2 \\
\text { (Time 1) }\end{array}$} \\
\hline Protestant & $46.8 \%(49.0 \%)$ & $47.4 \%(54.5 \%)$ \\
\hline Roman Catholic & $23.4 \%(26.5 \%)$ & $23.7 \%(22.7 \%)$ \\
\hline Other & $12.8 \%(10.2 \%)$ & $10.5 \%(11.3 \%)$ \\
\hline None & $17.0 \%(14.3 \%)$ & $18.4 \%(11.4 \%)$ \\
\hline \multicolumn{3}{|l|}{$\begin{array}{l}\text { Religious/spiritual self-Identification at Time } 2 \\
\text { (Time 1) }\end{array}$} \\
\hline More religious than spiritual & $15.2 \%(28.9 \%)$ & $16.2 \%(25.0 \%)$ \\
\hline Equally religious and spiritual & $41.3 \%(28.9 \%)$ & $40.5 \%(35.0 \%)$ \\
\hline More spiritual than religious & $26.1 \%(33.3 \%)$ & $29.7 \%(35.0 \%)$ \\
\hline Neither religious nor spiritual & $17.4 \% \quad(8.2 \%)$ & $13.5 \% \quad(5.0 \%)$ \\
\hline \multicolumn{3}{|l|}{ Deconversion } \\
\hline Traditionalist, reported at Time 1 and/or Time 2 & $36.7 \%(55.1 \%)$ & $35.6 \%(53.3 \%)$ \\
\hline $\begin{array}{r}\text { Deconversion Time 1, reported at Time } 1 \\
\text { (eventually confirmed at Time 2) }\end{array}$ & $44.9 \%(44.9 \%)$ & $46.7 \%(46.7 \%)$ \\
\hline $\begin{array}{r}\text { Deconversion between Time } 1 \text { and } 2 \text {, reported at } \\
\text { Time } 2\end{array}$ & $18.4 \%(00.0 \%)$ & $17.8 \%(00.0 \%)$ \\
\hline
\end{tabular}

Certainly, from the perspective of quantitative standards, the sample of re-interviewees is rather small: It consists of $n=37$ German and $n=8$ US participants who completed a second FDIwhich is $16.5 \%$ of the FDIs in the original Deconversion Study (Streib et al., 2009), where the FDI sample was $N=272$ (who were part of a questionnaire sample of $N=1,196$ ). While the project of a longitudinal study was developed during the deconversion study, and consequently, we asked participants for their permission to be contacted again, it is disappointing that we could not locate and successfully invite more participants for a second interview. Taking into account, however, that, in a time distance of ten years, former participants have moved, changed email, lost interest in our research, etc., we are thankful to all former participants in the Deconversion Study who accepted our invitation for a second interview. 
The consequences of this small-sample situation need some explication. One consequence is the decisive qualitative profile of the evaluations that are presented in this book, which, compared with other qualitative studies, can be regarded as based on a sample of acceptable size. And the rich information from a first and a second interview now allows the portrayal of changes as constructed by participants and as observed (double diachronicity), together with developments—of intra-individual differences.

Another consequence regards the role of quantitative analysis, which in the case of this study has to keep to the essential point of providing the quantitative background for the single cases or groups of cases and thus help to better understand stability and change in their development as far as this development is reflected in their questionnaire answers. Thus, the quantitative analyses that are presented here for this deconversion-revisited study have the function of contextualizing. We present intra- and inter-individual differences on selected scales and other quantitative to show trends that assist the interpretation of the single cases and their development over time.

\section{Religious Development of Deconverts and Traditionalists}

The key instrument to assess religious development in our research is the FDI (Fowler, 1981; Streib \& Keller, 2018). Forty-five participants were re-interviewed with the FDI. How can we compare the Time 1 FDIs with the Time 2 FDIs (intra-individual differences), the FDIs of traditionalists with the FDIs of deconverts (inter-individual differences A), and how can we determine the diversity within the groups of traditionalists and deconverts (inter-individual differences B)? While, of course, qualitative methods such as content analysis and narrative analysis will be applied in case studies as can be seen in case study chapters in this book, the classical avenue in evaluating the FDIs, from the beginning of FDI research (Moseley, Jarvis, \& Fowler, 1986), consists in the assignment of an overall religious style (or a "faith stage" in Fowler's terms) to the FDI as a whole. Such overall style assignment is supposed to yield an easy comparison of such inter-individual and intra-individual differences. We therefore begin with an explanation of our-recently revised (Streib, Chen, \& Hood, 2019)—construction of such overall assignment for the FDIs that allow a consistent comparison of FDIs from Time 1 or Time 2.

\section{Assessment of Religious Styles Development Based on the Construction of Types}

FDI evaluation is based on the rating of the answers to the 25 questions in the FDI, thus on the assignment of one of five styles to each of the answers (for more details, see Chapter 4 in this book; Streib \& Keller, 2018). These ratings are entered in the database as 25 variables with integers 1 through 5 for the five different categories. The challenge is that predominantly onestyle-only FDI ratings are rare, on the contrary, a combination of two or even three styles in one and the same interview is the rule, rather than the exception, as visualized in our so-called style-aspect profiles. Therefore, the construction of types/classes is the more plausible way for estimating the overall style assignment for an FDI.

We used a conceptual-model-based (CMB) algorithm for the assignment of types to the FDIs in our sample. This approach is specified by the following rules: Out of the 25 rating variables, 
if frequency of style 2 rating is equal to or more than 5 (20\%), the type is decided as Type 1 (substantially ethnocentric); if frequency of style 5 rating is equal to or more than 5 (20\%), the type is decided as Type 4 (emerging dialogical-xenosophic); else, the type is Type 2 (predominantly conventional) if frequency of style 3 rating is greater than that of style 4 rating, or Type 3 (predominantly individuative-reflective) if frequency of style 4 rating is greater than that of style 3 rating. A specific rule is set in place to break the ties introduced by an identical frequency of Style 3 and Style 4 rating, and/or both Style 2 and Style 5 ratings exceed 20\%. For these situations, the case should be associated with the "higher" type defined by the style rating frequencies.

Estimated mean rating percentages of styles 2, 3, 4, and 5 in the four religious types are presented in Figure 1; the estimation is based on ANOVA results using the total FDI sample in the Deconversion Study $(N=272)$.

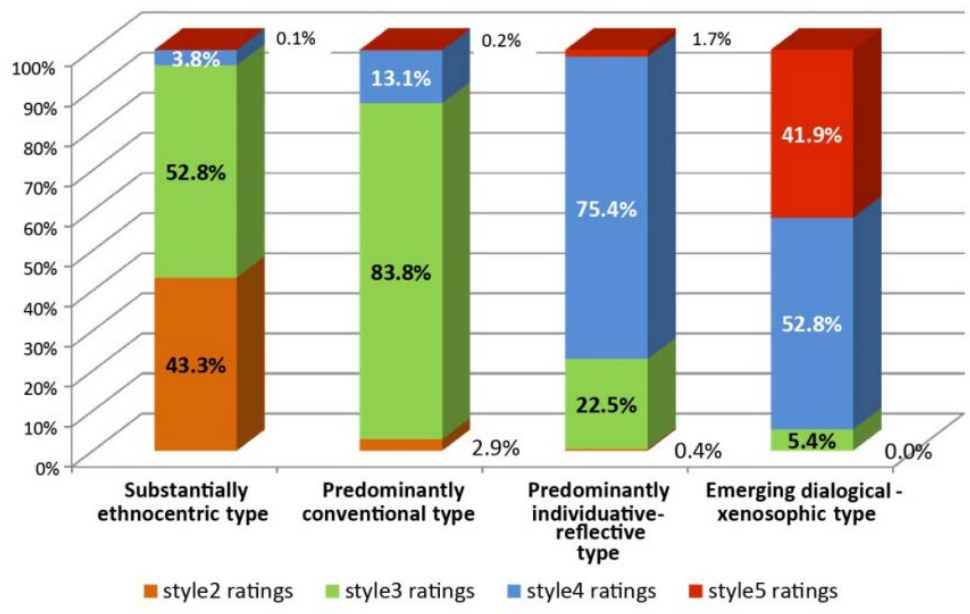

Figure 1. Religious Style Frequencies of the Religious Types in the Deconversion Sample at Time $1(N=272)$

The first column in Figure 1 presents, for the (substantially ethnocentric) Type 1, the ratings of style 2 with a portion of $43.3 \%$, and of style 3 with a portion of $52.8 \%$, while style 4 (3.8\%) and style $5(0.1 \%)$ are marginal. The second column shows, for the (predominantly conventional) Type 2, a distribution of $83.8 \%$ style 3 ratings and $13.1 \%$ style 4 ratings, while style 2 ratings (2.9\%) and style 5 ratings (0.2\%) are marginal. The third column presents, for the (predominantly individuative-reflective) Type 3, 75.4\% style 4 ratings and $22.5 \%$ style 3 ratings, while style 2 ratings $(0.4 \%)$ and style 5 ratings (1.7\%) are marginal. The last column presents, for the (emerging dialogical-xenosophic) Type 4, portions of $41.9 \%$ style 5 ratings and 52.8\% style 4 ratings, while style 3 ratings (5.4\%) are marginal and style 2 ratings are zero. Taken together, each of the four types has a clearly distinct profile as regards one characteristic religious style that stand out in the mixture of style assignments.

Hierarchical Order of the Four Religious Types

From our interpretation of the four religious types as substantially ethnocentric, predominantly conventional, predominantly individuative-reflective, and emerging dialogical-xenosophic, it is 
obvious that the four types consist of four "typical" configurations of the religious styles (Streib, 2001) which are supposed to occur in adult samples, and that these reflect four of Fowler's (1981) six stages of faith. The unique characteristic of the four types, and the difference between them, is the proportional strength of certain styles-quite similar to the construction of personality types that represent the five personality traits. ${ }^{2}$ Thus the difference between styles and types is primarily this: Types reflect what we find in the interviews, namely, very often, a mix of styles. And thereby a type indicates the predominant or substantial style, while not ignoring that there is or can be more than one style in the same interview text.

Because the four types are rooted in the models of religious styles and stages of faith, they present a hierarchical order. This hierarchical order of the types is plausible especially on philosophical-ethical and phenomenological grounds: Xenosophia and dialog are ethically higher than mere individuative reflection and tolerance (Streib, 2018). Reflection and tolerance are, in turn, ethically higher than mere conventionalism. And all of the above are ethically higher than ethnocentric attitudes and mythic-literal understanding.

\section{Differences Between Traditionalists and Deconverts in the Religious Types}

As explained in the beginning of this chapter, in the original Deconversion Study (Streib et al., 2009), we paid special attention to the contrast between deconverts and traditionalists. And one of the remarkable results reported in the first study was that, compared to traditionalists, religious development of deconverts is more advanced. Here we not only present a revised assessment that is based on the newly constructed four religious types (which is the final "score" in FDI evaluation), but also, we can now determine whether this group difference was stable over time of the approximately ten years between the FDI at Time 1 and the more recent reinterview at Time 2. Figure 2 shows results from two cross-tabulations of assignments to one of the four religious types with distinct attention to traditionalists and deconverts: Two columns on the left present all FDIs in the Deconversion Sample at Time 1, the two columns on the right present the re-interviewees at Time $2 .^{3}$

The figure shows that, compared to the group of traditionalists, a considerably higher percentage of deconverts are assigned to the predominantly individuative-reflective type at both Time 1 and Time 2-with a slight decline of this difference at Time 2. Correspondingly, a lower percentage of deconverts than traditionalists are assigned to the predominantly conventional type at both Time 1 and Time 2-with a moderation of this difference for Time 2. And, the new deconverts at Time 2 apparently reflect the deconvert pattern. This confirms that deconverts are more advanced in religious styles development than traditionalists, and that this difference is demonstrated for Time 1 and Time 2. Thus, the more advanced religious styles development of deconverts appears to be a largely stable pattern.

\footnotetext{
2 This approach to type construction parallels type constructions in personality research (Asendorpf, Borkenau, Ostendorf, \& van Aken, 2001; Gerlach, Farb, Revelle, \& Nunes Amaral, 2018), even though, considering the sample size, our analysis cannot compete with these studies.

${ }^{3}$ The number of traditionalists and deconverts at Time 2 (together $N=53$ ) includes eight cases for which we have questionnaire data at Time 1 and Time 2, but no FDI at Time 1.
} 


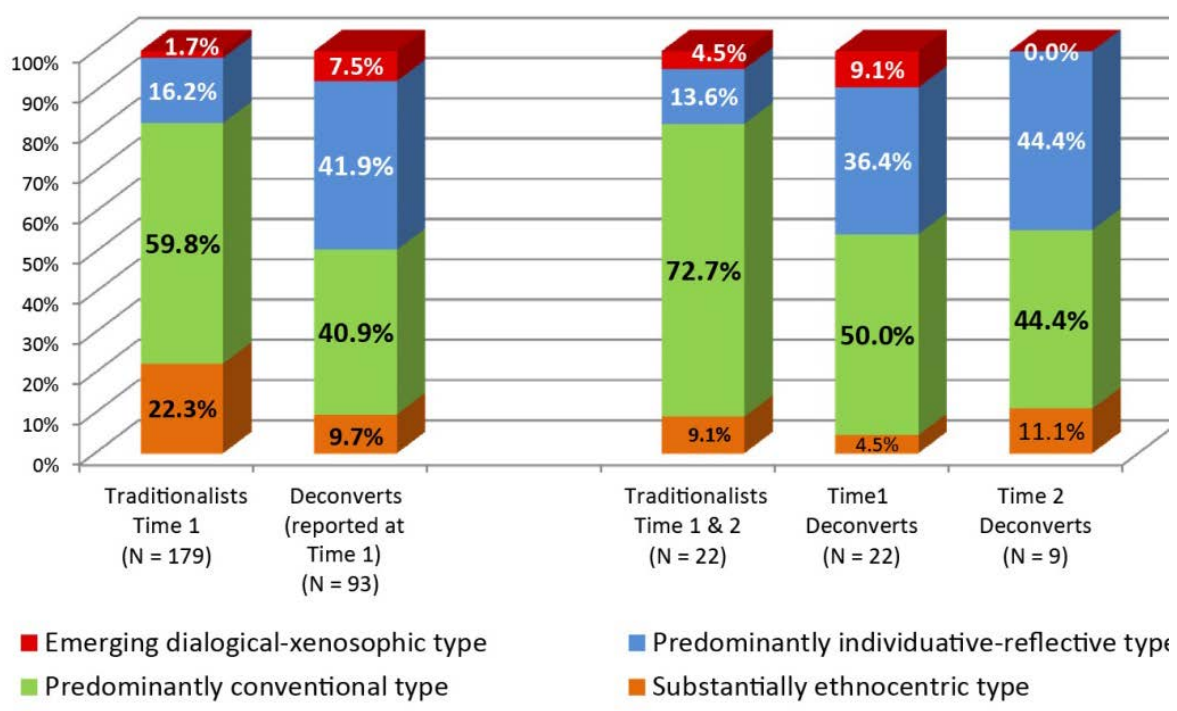

Figure 2. Frequency of Religious types in Traditionalists and Deconverts at Time 1 and Time 2

\section{Movers and Stayers in the Sample}

Figure 3 presents a migration diagram for the $N=45$ cases from the Deconversion Sample with FDI evaluation and an assignment of a religious type at Time 1 and Time 2.

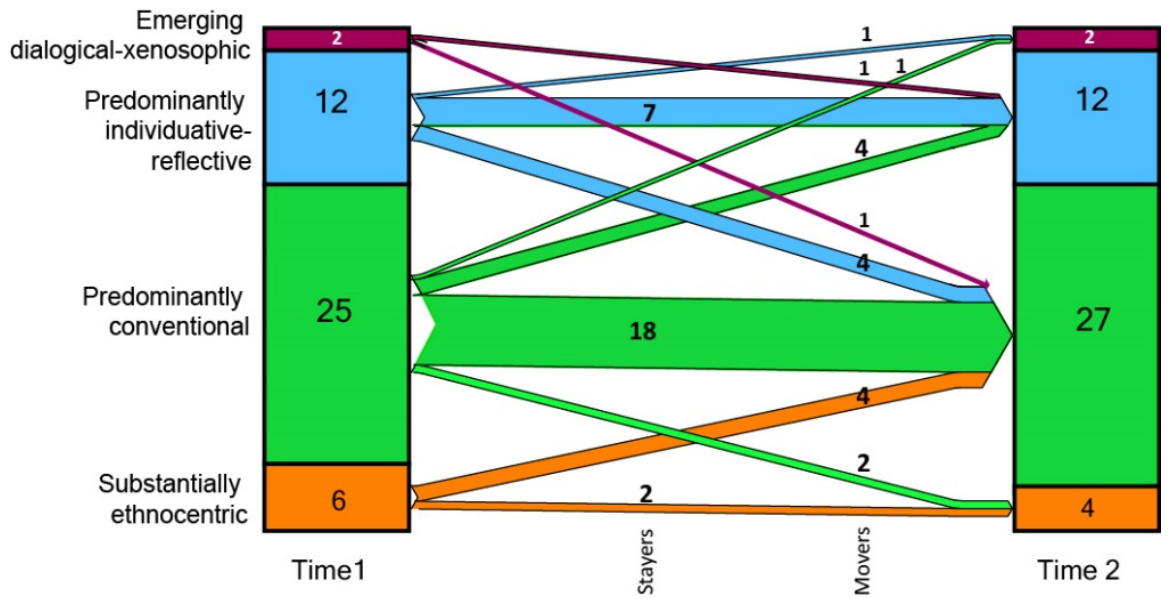

Figure 3. Migrations of Movers and Stayers in Deconversion Sample between Time 1 and 2

Both columns left and right in Figure 3 present the numbers of cases that were assigned to one of the four religious types at Time 1 and Time 2. And attention to both columns alone would suggest high stability and only marginal change, because the distribution of types appears almost the same. But attention to the arrows reveals much higher migration; the arrows identify movers and stayers. Certainly, the figure shows that there is more stability than change in this re-interviewee sample; but only $60 \%$ are stayers who have kept their religious type over ten years between the first and the second interview. And interestingly, but not very surprisingly, 
the individuals with the predominant conventional type are the most stable group with the highest proportion of stayers.

Forty percent of our longitudinal sample consists of movers. And movements are going upwards and downwards - which, based on the assumption that the order of our four religious types reflects a developmental hierarchy, can be labeled movers "upward" to a "higher" type, and movers "downward" to a "lower" type. The existence of movers downward presents a challenge to the assumption of a mono-directional progressive development. On the contrary, Figure 3 documents a variety of migration paths that include stayers and movers upwards, but also movers downwards.

These results clearly demonstrate that these re-interviewees from the Deconversion Project have walked a variety of developmental paths. Information about the reasons why individuals are stayers, movers upward, or movers downward could be expected from attending to their questionnaire responses, but especially by attention to the narratives in their interviews. And to prepare an overview on the case studies, it may be helpful to present migration information of all re-interviewees individually.

\section{Type Migration of Individual Cases}

Because this quantitative overview is aiming at profiling the re-interviewee sample with attention to the individual cases and thus prepare case study construction, we present the reinterviewee sample case by case in Table 2. This table is sorted for movers and stayers in order to easily identify these groups. Type assignments are given for both times of measurementwhich allows a more precise assessment of the developmental trajectory of the individual case. Finally, we included the information in the table, whether the individual cases continued membership in their religious tradition, had identified as deconverts at the first time of interviewing, or whether they identified as deconverts at Time 2 interviewing. 
Table 2. Type Membership of Individual Cases in the Re-Interviewee Sample

\begin{tabular}{|c|c|c|c|c|}
\hline Pseudonym & Deconvert or Traditionalist? & $\begin{array}{c}\text { Type at } \\
\text { Time1 }\end{array}$ & $\begin{array}{l}\text { Type at } \\
\text { Time2 }\end{array}$ & Stayer or Mover? \\
\hline Wolfgang & Traditionalist (reported at Time1; Time2) & Type2 & Type2 & Stayer \\
\hline Werner & Deconvert (reported at Time1) & Type2 & Type2 & Stayer \\
\hline Sylvia Marie & Deconvert (reported at Time1) & Type3 & Type3 & Stayer \\
\hline Sebastian & Deconvert (reported at Time1) & Type3 & Type3 & Stayer \\
\hline Richard & Traditionalist (reported at Time1; Time2) & Type2 & Type2 & Stayer \\
\hline Renate & Traditionalist (reported at Time1; Time2) & Type2 & Type2 & Stayer \\
\hline Petra & Deconvert (reported at Time1) & Type3 & Type3 & Stayer \\
\hline Peter Michael & Deconvert (reported at Time1) & Type2 & Type2 & Stayer \\
\hline Paris & Deconvert (reported at Time1) & Type2 & Type2 & Stayer \\
\hline Noel & Traditionalist (reported at Time1; Time2) & Type1 & Type1 & Stayer \\
\hline Mia & Deconvert (reported at Time1) & Type3 & Type3 & Stayer \\
\hline Lucy & Deconvert (reported at Time1) & Type1 & Type1 & Stayer \\
\hline Julia & Deconvert (reported at Time1) & Type2 & Type2 & Stayer \\
\hline Josef & Traditionalist (reported at Time1; Time2) & Type2 & Type2 & Stayer \\
\hline Jörg & Traditionalist (reported at Time1; Time2) & Type2 & Type2 & Stayer \\
\hline Jannis & Traditionalist (reported at Time1; Time2) & Type2 & Type2 & Stayer \\
\hline Gisela & Traditionalist (reported at Time1; Time2) & Type2 & Type2 & Stayer \\
\hline Gerhard & Deconvert (reported at Time1) & Type2 & Type2 & Stayer \\
\hline Donna & Deconvert (reported at Time1) & Type3 & Type3 & Stayer \\
\hline Dennis & Deconvert (reported at Time1) & Type2 & Type2 & Stayer \\
\hline Dale & Deconvert (reported at Time1) & Type3 & Type3 & Stayer \\
\hline Corinna & Traditionalist (reported at Time1; Time2) & Type2 & Type2 & Stayer \\
\hline Carola & Deconvert (reported at Time1) & Type2 & Type2 & Stayer \\
\hline Bianca & Traditionalist (reported at Time1; Time2) & Type2 & Type2 & Stayer \\
\hline Bernhard & Deconvert (reported at Time2) & Type3 & Type3 & Stayer \\
\hline Antje & Deconvert (reported at Time2) & Type2 & Type2 & Stayer \\
\hline Angelika & Deconvert (reported at Time2) & Type2 & Type2 & Stayer \\
\hline Ulrich & Deconvert (reported at Time2) & Type1 & Type2 & Mover upward \\
\hline Sophia & Deconvert (reported at Time1) & Type3 & Type4 & Mover upward \\
\hline Siegfried & Traditionalist (reported at Time1; Time2) & Type2 & Type3 & Mover upward \\
\hline Martin & Deconvert (reported at Time2) & Type2 & Type3 & Mover upward \\
\hline Heidemarie & Traditionalist (reported at Time1; Time2) & Type1 & Type2 & Mover upward \\
\hline Gudrun & Deconvert (reported at Time1) & Type1 & Type2 & Mover upward \\
\hline Gabi & Deconvert (reported at Time2) & Type2 & Type3 & Mover upward \\
\hline Franziska & Deconvert (reported at Time1) & Type2 & Type4 & Mover upward \\
\hline Emilia & Deconvert (reported at Time2) & Type2 & Type3 & Mover upward \\
\hline Britney & Traditionalist (reported at Time1; Time2) & Type1 & Type2 & Mover upward \\
\hline Roswitha & Traditionalist (reported at Time1; Time2) & Type3 & Type2 & Mover downward \\
\hline Reginald & Traditionalist (reported at Time1; Time2) & Type3 & Type2 & Mover downward \\
\hline Ralf & Deconvert (reported at Time1) & Type3 & Type2 & Mover downward \\
\hline Melvin & Traditionalist (reported at Time1; Time2) & Type2 & Type1 & Mover downward \\
\hline Konrad & Deconvert (reported at Time1) & Type4 & Type3 & Mover downward \\
\hline Dominik & Deconvert (reported at Time1) & Type4 & Type2 & Mover downward \\
\hline Cordula Susanne & Deconvert (reported at Time1) & Type3 & Type2 & Mover downward \\
\hline Berthold & Deconvert (reported at Time2) & Type2 & Type1 & Mover downward \\
\hline
\end{tabular}




\section{Spiritual and Religious Self-Identification}

We reported in the 2009 Deconversion Book (Streib et al., 2009) an unexpectedly large difference between traditionalists and deconverts in regard to religious/spiritual selfidentification. In fact, this unexpected result was one of the reasons why we started to engage in the investigation of the semantics and psychology of self-identified "spirituality" (Streib \& Hood, 2016). To focus on the German sample here, ${ }^{4}$ the portion of "more spiritual than religious" deconverts (36.5\%) has doubled the number of "more spiritual than religious" traditionalists (18.4\%) in the Deconversion Study data; the results in the two columns on the left of Figure 4 have been presented in the 2009 Deconversion Book (Streib et al., 2009).

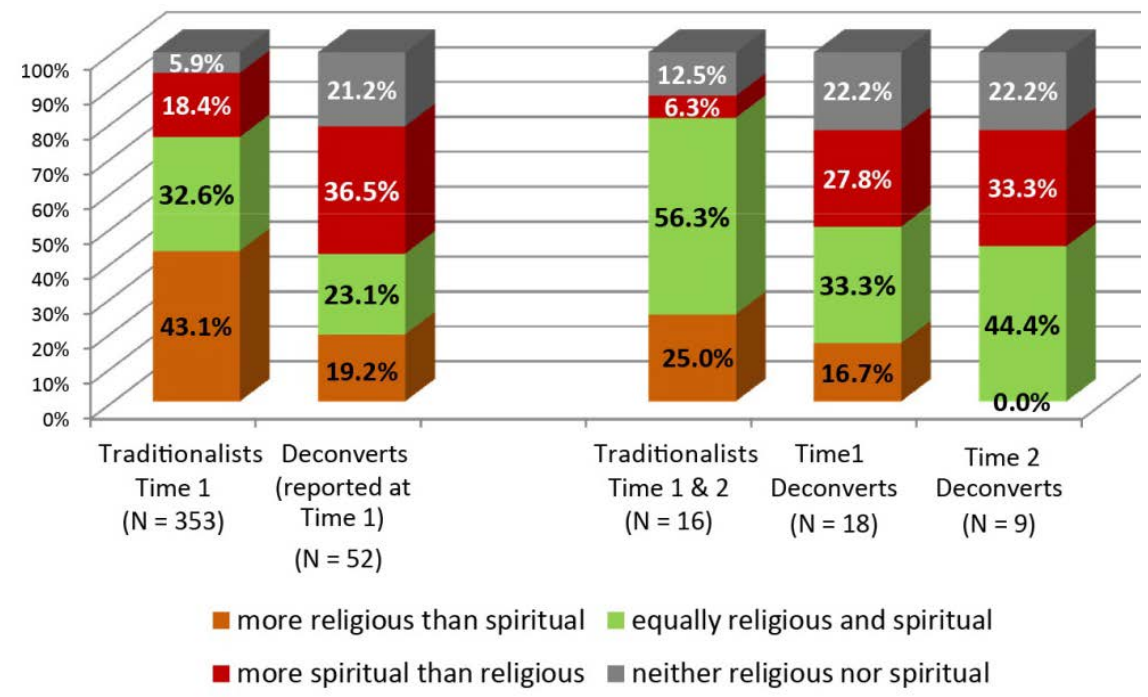

Figure 4. Spiritual/Religious Self-Identification of German Re-Interviewees from the Deconversion Project

Now, after the second wave of interviewing, we can address the question whether this extraordinary difference in spiritual self-identification has been stable overtime and/or deconverts self-identify as "more spiritual" in higher numbers. The columns on the right in Figure 4 present results for the German re-interviewee sample. Indeed, Time 1 deconverts appear to have mainly continued their higher preference for "more spiritual” self-identification. And interestingly, the Time 2 deconverts also self-identify in higher numbers as "more spiritual.” This could be an indication that deconversion at Time 1 and Time 2 is related to a preference for "more spiritual" self-identification. In contrast, the traditionalists reveal at Time 2 that they are reluctant to self-identify as "more spiritual." Interesting also is the general decline of "more religious than spiritual" self-identification in this German re-interviewee sample between Time 1 and Time 2. These results may allow for the tentative conclusion that deconversion is associated with the preference for "more spiritual than religious" selfidentification and this preference may be generally stable over the years.

\footnotetext{
${ }^{4}$ In this and some analyses to follow, we include only the German sample, because there were not enough questionnaire participants for US re-interviewees at Time 2.
} 


\section{Religious Schemata}

We assume that the religious schemata are related to and indicate religious development as documented by the four religious types. And as the distribution of the four types is considerably different between the group of traditionalists and the two groups of deconverts (see Figure 2), also the three subscales of the Religious Schema Scale (Streib et al., 2010), truth of text and teachings (ttt), fairness, tolerance, and rational choice (ftr), and xenosophia/inter-religious dialog (xenos), account for the difference between traditionalists and deconverts—and for the changes between two times of measurement.

As noted above, in the first Deconversion Study at Time 1, all three RSS subscales have differentiated between traditionalists and deconverts in the US sample, while for the German participants only the difference in $t t$ reached significance (Streib et al., 2009, p. 74). Time 1 deconverts, much more than traditionalists, in both the US and the German sample were reluctant to agree to the truth of their religious tradition. Was this difference in $t t t$ stable over time? The results including the second-wave data present an affirmative answer, which is also visualized in Figure 5.

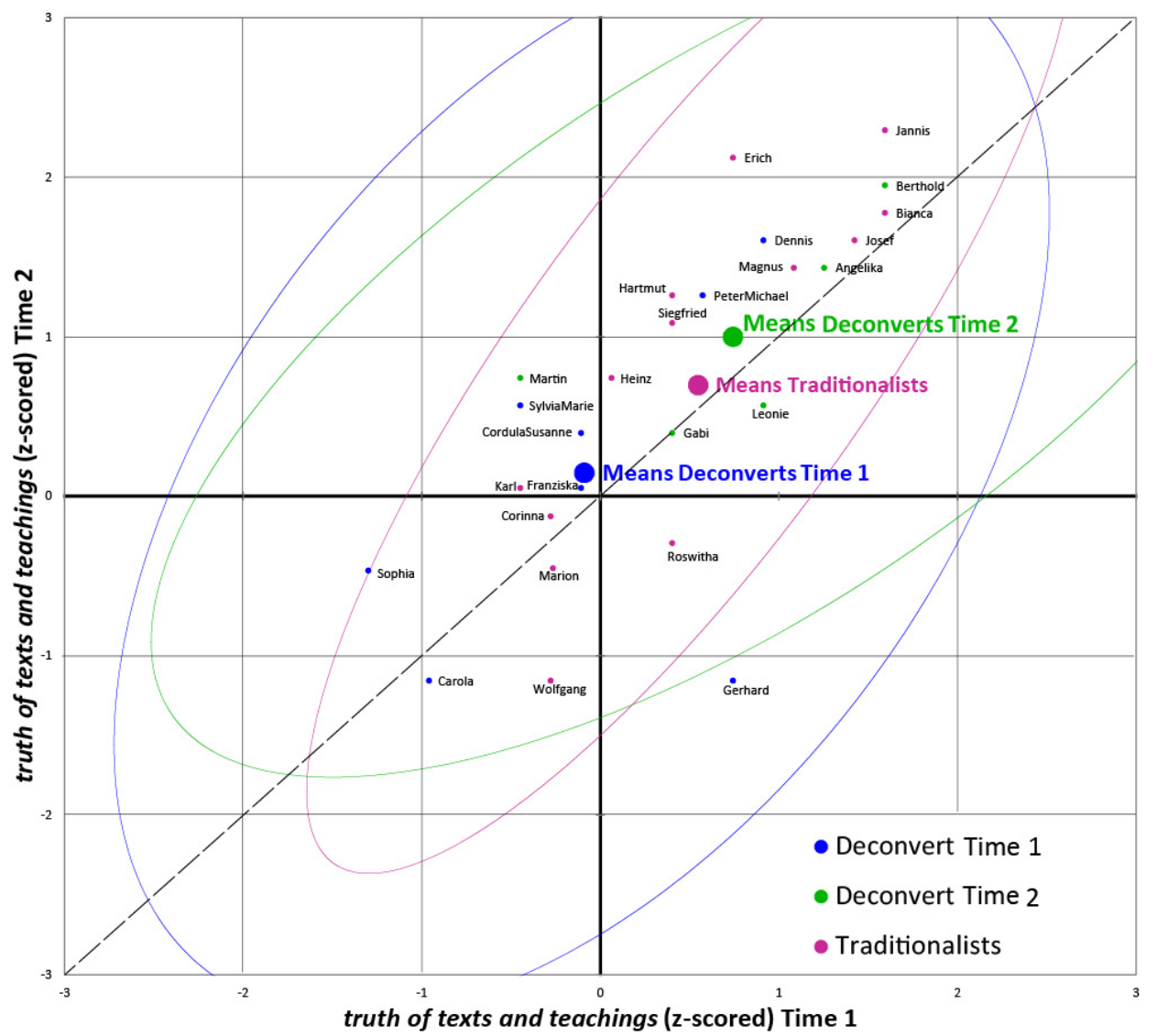

Figure 5. Changes in Truth of Text and Teachings (RSS) in Traditionalists and Deconverts

Figure 5 is the first of a series of figures that are used here to visualize changes between Time 1 and Time 2 on selected variables in our data. We use scatter plots, because they allow attention to the single cases and their development-with the intent to assist case studies. For easier 
identification of standard deviations, values are z-standardized. In addition, we include the mean values for the groups of traditionalists and deconverts and 95\% confidence ellipses, in order to visualize mean difference (that are not significant in all figures however). Time 1 values (x) and Time 2 values (y) are vectors to determine the location of the cases in the twodimensional space. The diagonal (dotted line) indicates equal scores at both times of measurement; a position above the diagonal indicates higher values at Time 2, while a position below indicates lower scores at Time 2. This way, we can plot growth and decline, development and regression according the respective dimensions.

Now back to Figure 5 and the analyses of changes in $t t t$. The relations displayed in Figure 5 did not reach significance in multivariate analysis of variance. Nevertheless, when analyzed in an UNIAOVA with exclusive attention to Time 2, the difference between traditionalists and Time 1 deconverts on $t t t$ is significant with $F_{(2,39)}=5.26$, $(p=.010)$, suggesting that this difference continued over the time of 10 years. Deconverts at Time 1 appear to remain stable in their low agreement to the texts and teachings of their (former) religious tradition.

Unexpectedly however, the assumption that Time 2 deconverts will have lower $t t$ scores after their deconversion between Time 1 and Time 2 was not confirmed. The means of Time 2 deconverts appears to be higher than the means of traditionalists, but the difference is not significant. This may suggest some caution toward the assumption that every deconversion is associated with lower ttt. Besides questions of significance for between-groups difference, the figure is important in regard to the position of the single cases.

Also, Figure 6 for the RSS subscale xenosophia/inter-religious dialog may be helpful especially for single cases, while between-group differences are not significant and the slightly higher mean scores for both groups of deconverts is not more than the indication of a trend in the expected direction. 


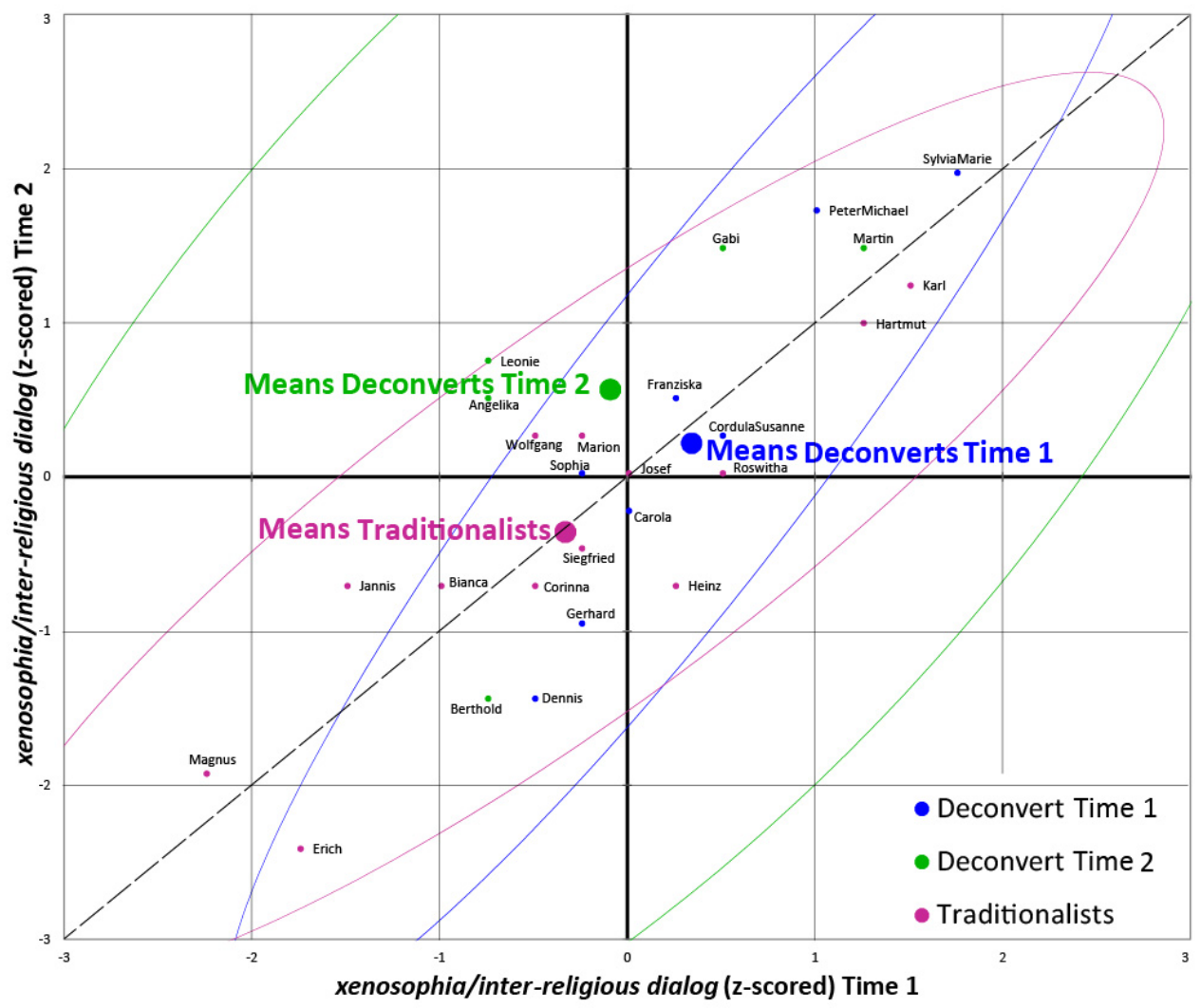

Figure 6. Changes in Xenosophia/Inter-Religious Dialog (RSS) in Traditionalists and Deconverts

\section{Personality}

Of the "big five" personality factors, only openness to experience has marked a significant difference between traditionalists and deconverts at Time 1 in both countries, while differences on agreeableness and conscientiousness were significant for the German sample only. But this was analyzed using the total first-wave deconversion sample. Figure 7, however, is based on the re-interviewee sample only and shows no significant differences between the groups at all. We may assume that this unexpected result is explained by the characteristic of the sample (which consists of the relatively small number of re-interviewees who could be located and successfully invited). But our assumption that openness to experience will have an effect on group differences between traditionalists and deconverts also at Time 2 is not confirmed. Nevertheless, Figure 7 may, again, be helpful for the interpretation of single cases, especially the cases with one or more standard deviations, or with major gains or losses in openness to experience between their Time 1 and Time 2 interviews. 


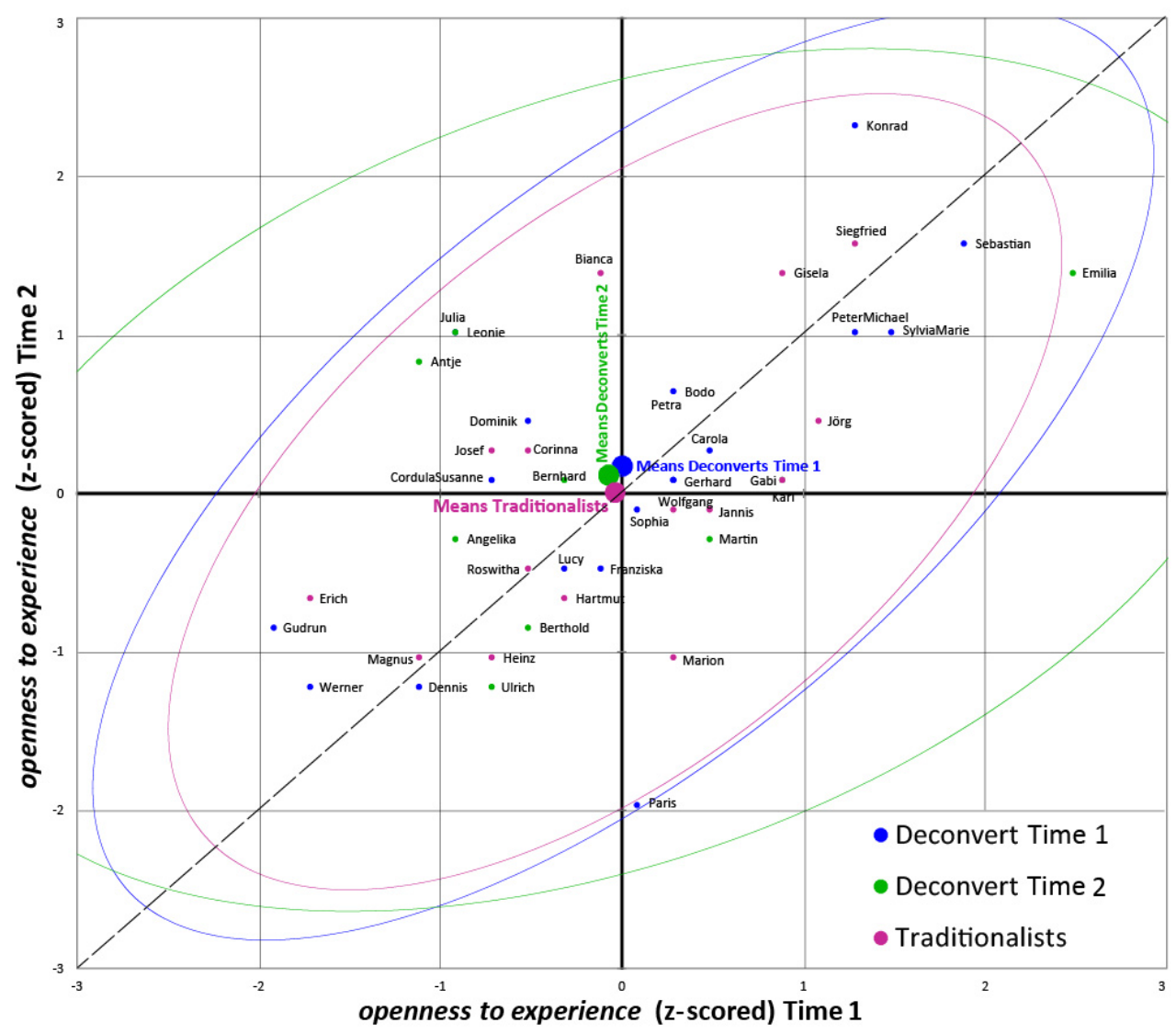

Figure 7. Changes in Openness to Experience (NEO-FFI) in Traditionalists and Deconverts

On other personality factors, analyses of Time 1 data have indicated significant differences between traditionalists and deconverts for the German sample only (Streib et al., 2009, p. 74). Specifically, there were lower scores of deconverts on emotional stability, agreeableness, and conscientiousness. Now, using the re-interviewee data from both times of measurement, results indicate no significant differences on conscientiousness, while scores on agreeableness are significant in regard to between-group differences, and also differences on emotional stability tend to be significant.

Interestingly, the deconversion experience appears to be related to the personality factor of emotional stability (neuroticism reversed), but only for our German deconverts. This had been documented for the participants in first Deconversion Study (Streib et al., 2009, p. 74). Now, the second-wave data allow some inspection of the changes over time, and also the effects of more recent deconversions - even though only tentatively, because multivariate analysis of variance of the relations that are visualized in Figure 8 indicates that, with Hotelling's $T^{2}=9.91$ $(p=.062)$, differences are somewhat below the threshold for significance, even if $\eta^{2}=.11$ indicates a middle effect size. 


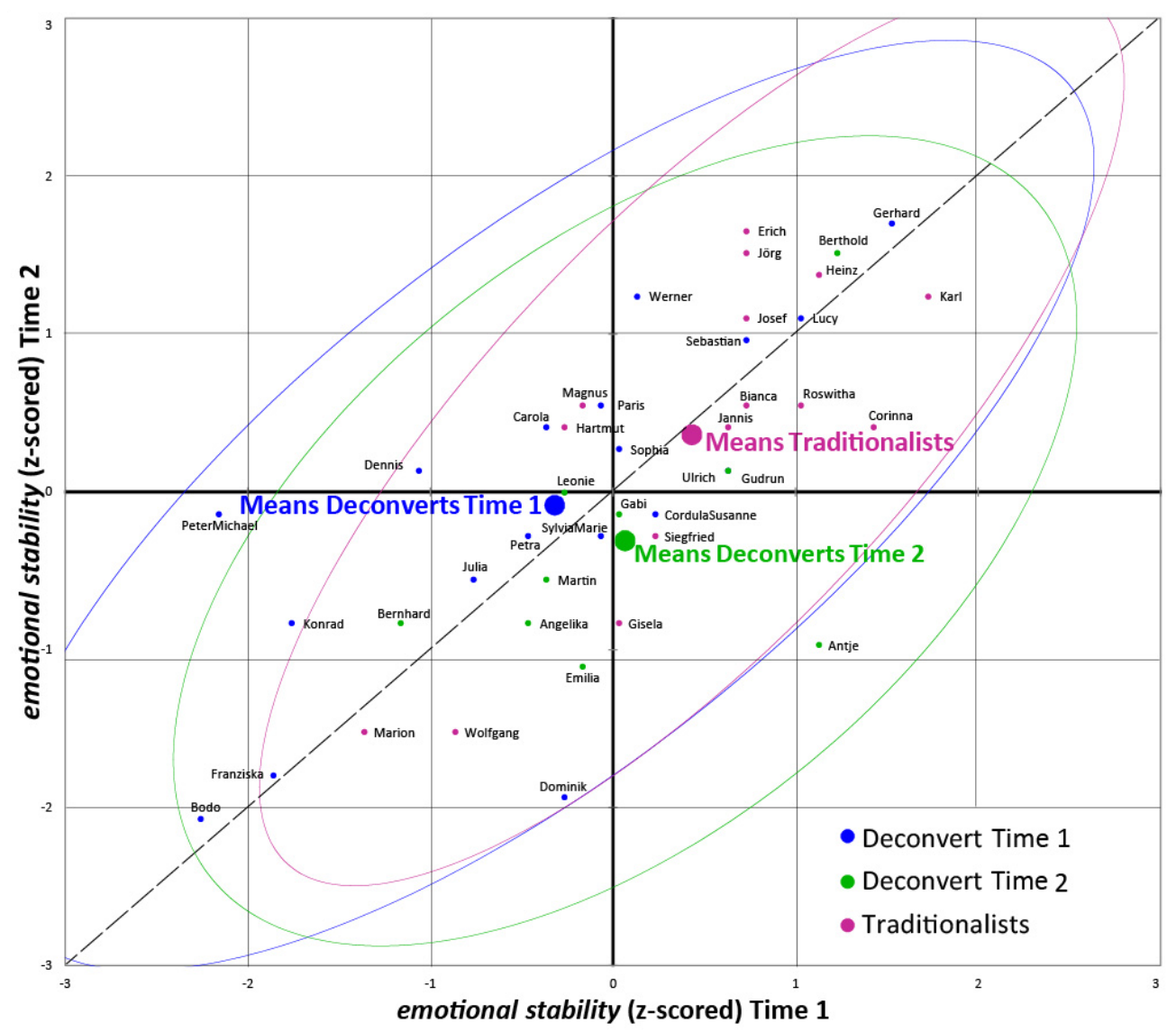

Figure 8. Changes in Emotional Stability (NEO-FFI) in Traditionalists and Deconverts

Thus, interpreting Figure 8 with due caution, emotional stability of traditionalists appears to be higher and rather stable over the distance between Time 1 and Time 2. Time 1 deconverts, in contrast, had considerably lower emotional stability at Time 1, but obviously gained some emotional stability at Time 2. Interestingly, Time 2 deconverts had already lower emotional stability at Time 1 than traditionalists, but have declined in emotional stability at Time 2. This could be an indication that some challenge to emotional stability is related to deconversion in the more recent past. Because the majority of 94\% of the cases in Figure 8 are German participants, this would confirm the observations in the first Deconversion Study that, for Germans at least, deconversion can be associated with the experience of loss and crisis.

Finally, we present changes over time and the differences between traditionalists and deconverts in the personality factor of agreeableness in Figure 9. For agreeableness the between-group differences are significant (Hotelling's $T^{2}=15.48, p=.009$ ) and the effect size is large $\left(\eta^{2}=.17\right)$. As can be seen in the figure on first sight, the largest difference exists between traditionalists and Time 1 deconverts, for which Post-Hoc Tests reveal that they exceed one standard deviation at both times of measurement $\left(\Delta M_{\text {Time1 }}=1.06, p=.005\right.$ and $\Delta M_{\text {Time2 }}=1.11$, $p=.003$ ). Agreeableness appears to be a fairly stable personality trait, and (our mostly German) deconverts appear to be generally lower on this personality trait-with interesting differences between Time 1 and Time 2 deconverts, however. The participants, who have deconverted between Time 1 and Time 2 and who at Time 1 still identified as traditionalist, appear to be only slightly lower on agreeableness, and scores on agreeableness have remained fairly stable between both times of measurement. This may indicate that low agreeableness may be a clear 
correlate to, or even a predictor for, deconversion, but not for all cases. We cannot conclude with a general deconversion-agreeableness relation from results on this relatively small data base. But still the positions of the single cases in the two-dimensional space indicate individual differences and may help to better understand their motifs for their deconversions or continuation of affiliation, respectively.

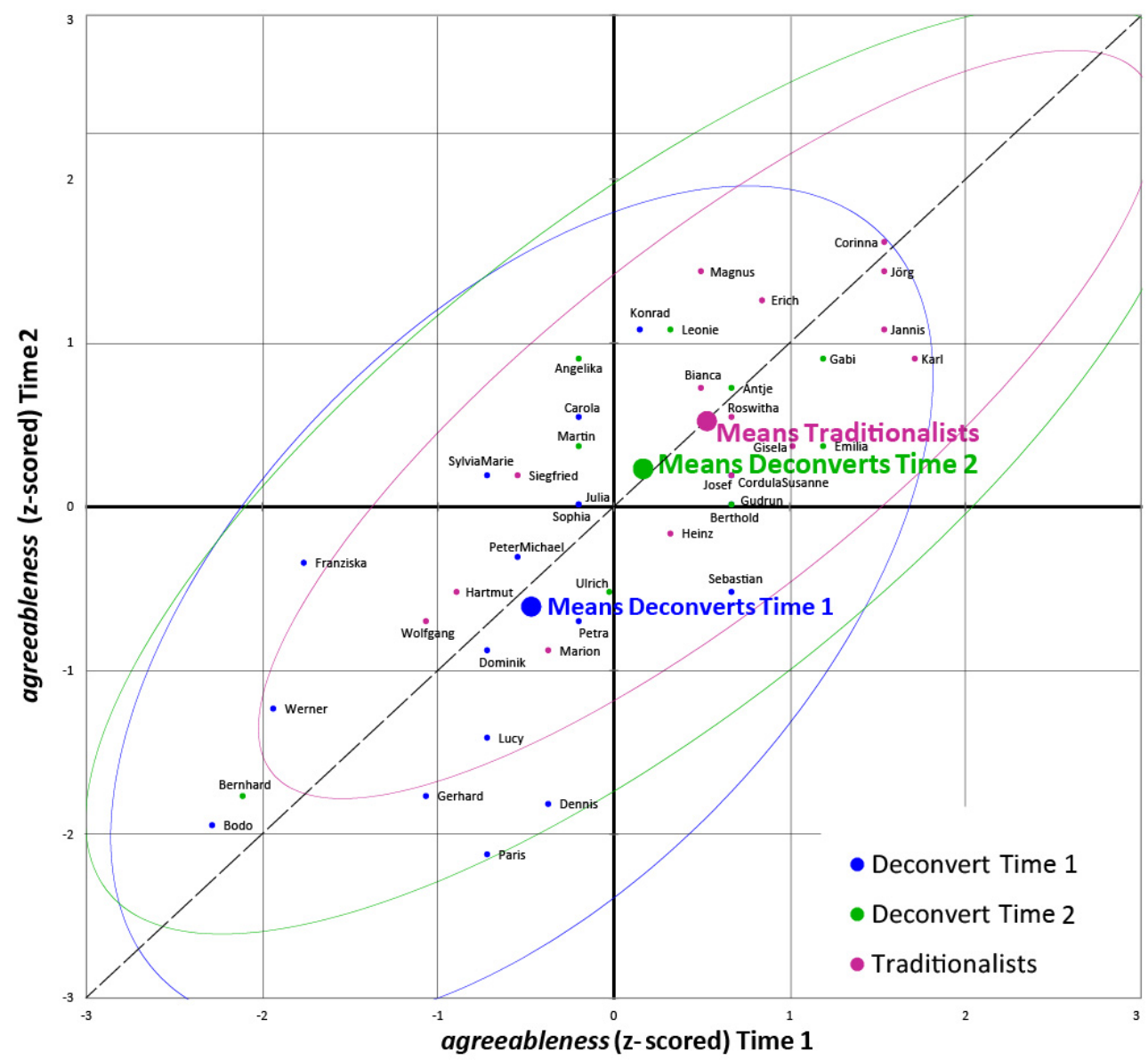

Figure 9. Changes in Agreeableness (NEO-FFI) in Traditionalists and Deconverts

\section{Psychological Well-Being and Growth}

In a final step, we attend to the results on well-being. Results at Time 1 revealed lower scores on environmental mastery, positive relations with others, purpose in life, and self-acceptance for the German deconverts - which we have interpreted as "signs of a loss or a crisis" (Streib et al., 2009, p. 81). Now, including our second-wave data, we may move to the question whether this loss or crisis continued over the time distance of ten years or whether the German deconverts who were re-interviewed have experienced some recovery in the meantime. For new Time 2 deconverts in Germany, we have assumed that their scores on environmental mastery, positive relations with others, purpose in life, and self-acceptance indicate a similar loss and crisis as revealed for the Time 1 deconverts ten years ago. Now, while results on environmental mastery and positive relations with others were not significant, purpose in life and self- 
acceptance are. Thus, these two dimensions of the Psychological Well-Being and Growth Scale are presented in the following.

On purpose in life, between-groups differences are again significant (Hotelling's $T^{2}=11.82, p$ $=.032$ ) and effect size of difference is large $\left(\eta^{2}=.13\right)$. Results indicate an interesting triangle that is visualized in Figure 10. Traditionalists appear as stable over the years on purpose in life on a higher level than deconverts. Also, Time 1 deconverts, as hypothesized, appear as stable on a clearly lower level. But the means for Deconverts Time 1 in Figure 10 would move to the zero line, when we would exclude the three US deconverts (Fiona, Paris, and Lucy) from the analysis. These three Time 1 deconverts in the US sample pull the means dot down (they need to be presented nevertheless, because of the case studies). But attending exclusively to the German Time 1 deconverts indicates their moderate improvement on purpose in life over the ten years between their first and second interview.

Further, it is the Time 2 deconverts who present another interesting finding: Their scores on purpose in life appear to be almost one standard deviation lower than that of the traditionalists. We may conclude from this that, corroborating results from the first Deconversion Study, deconversion may be associated with signs of a loss or a crisis, which here is documented for purpose in life.

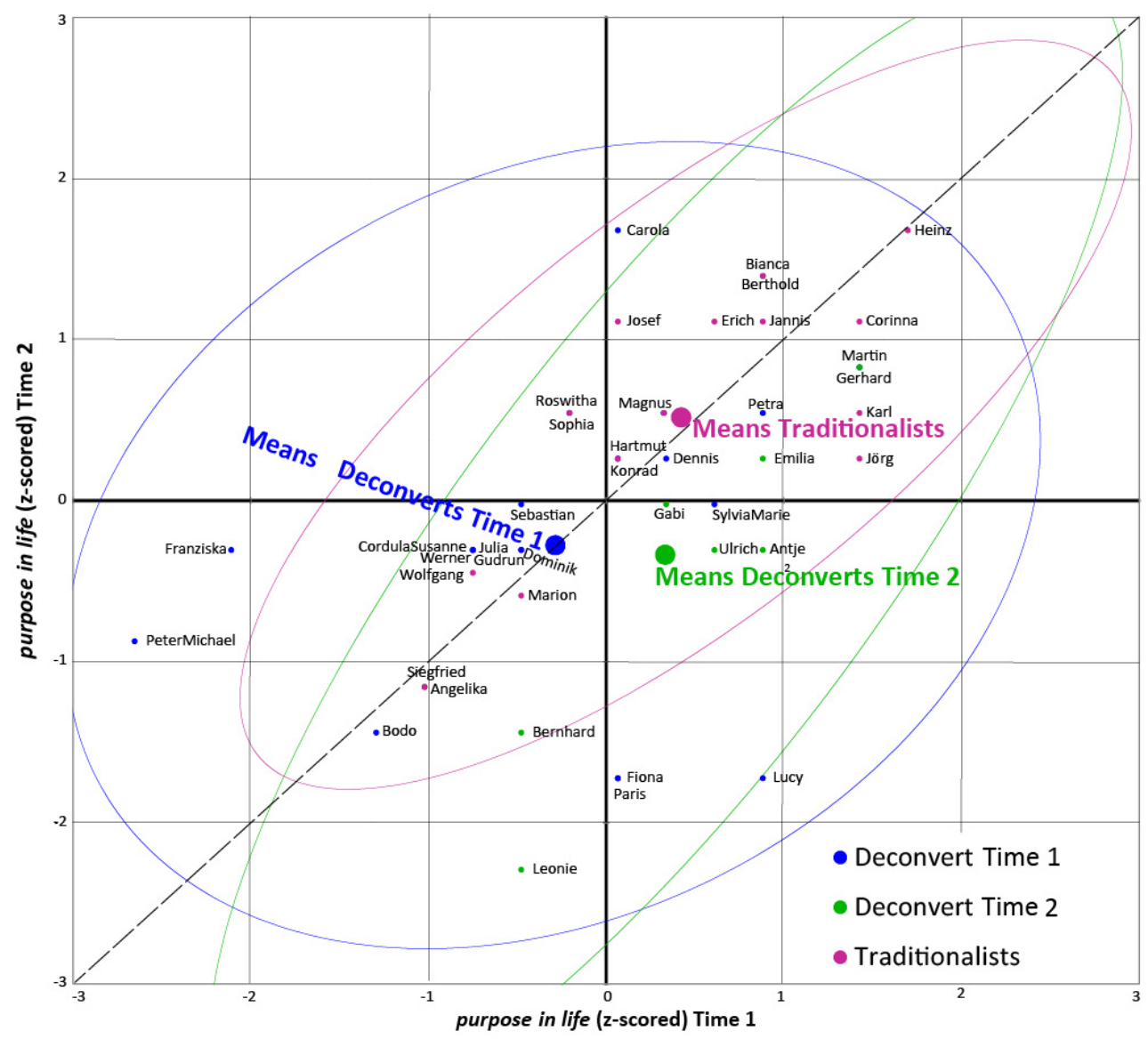

Figure 10. Changes in Purpose in Life (Ryff-Scales) in Traditionalists and Deconverts 
Taken together, deconversions that occurred in the more recent past appear to be associated with lower scores on purpose in life, but may somewhat improve and recover in a time of ten years, as if time heals wounds.

On self-acceptance, finally, a similar picture emerges (see Figure 11): Traditionalists appear as rather stable on a relatively high level, with signs of a slight increase of their self-acceptance between the two times of measurement. Deconverts at both times of measurement, in contrast, have clearly lower scores on self-acceptance. Differences on self-acceptance are significant (Hotelling's $\left.T^{2}=14.86, p=.011\right)$ and have a large effect size $\left(\eta^{2}=.16\right)$.

Lower mean scores for deconverts also on self-acceptance may be an indication of a loss or a crisis that is associated with deconversion. And also on self-acceptance, but with lower difference, the means for Deconverts Time 1 would be slightly higher and located beyond the dotted line for stability-indicating some recovery for Time 1 deconverts of the ten years.

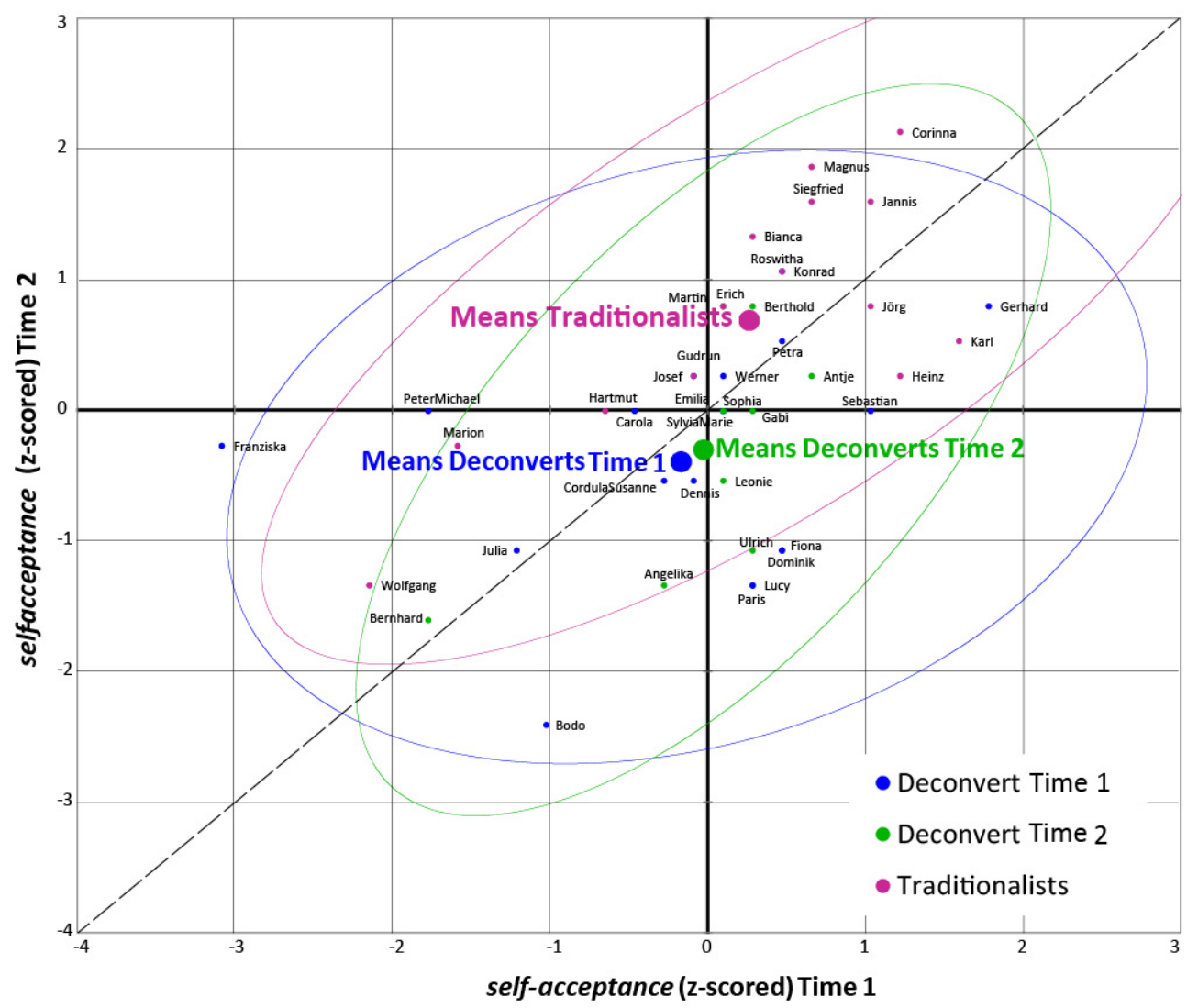

Figure 11. Changes in Self-Acceptance (Ryff-Scales) Between Traditionalists and Deconverts

\section{Conclusion}

The analyses presented in this chapter had a comparative perspective with a special focus on deconverts. In continuation of our first Deconversion Study, the distinction between traditionalists and deconverts has been the most important, and has revealed interesting results. We hypothesized that most central findings from the first Deconversion Study will be 
confirmed by the results of this second wave of data. And indeed the new data confirm that deconverts are more advanced in religious styles, since deconverts feature the predominantly individuative-reflective type in higher numbers. We also found confirmation for deconverts' higher preference for "more spiritual" self-identification. That both more advanced religious development and higher "spiritual" preference is revealed also for the participants who deconverted between the first and the second wave of investigation makes such confirmation of results from the first wave even stronger.

It is the great potential of longitudinal data that they yield insight in development. And this chapter has presented the quantitative results on change and stability between Time 1 and Time 2 of investigation. Given that the sample of re-interviewees is rather small, the aim in this chapter was profiling the sample statistically, while always keeping in mind that results should assist the interpretation of the single cases and help to better understand their trajectories. For visualizing, therefore, we have decided for scatter plots that allow inspection of the single case.

Regarding religious development as process over time, which is an important focus in our research, our results do not support models that assume a simple progressive line of development. On the contrary, the existence of movers downward-participants who moved to a lower religious type at Time 2-presents a challenge to the assumption of a mono-directional upward development. Of course, the results presented here do not allow conclusions for a general model of religious development, because they are based on a relatively small sample. But these results are in line with the assumption that religious styles development does not follow a mono-directional upward line of developmental progress, but rather present us with a variety of migration paths. Our results demonstrate that the re-interviewees from the Deconversion Project have walked a variety of developmental paths in regard to religious styles development. What caused this difference in developmental paths is a very interesting question, but cannot be answered quantitatively on the basis of this small deconversion revisited sample. Only single case studies may discover some more details, case-specific of course.

The project of deconversion revisited includes an investigation of stability and change of deconverts and traditionalists between Time 1 and Time 2. Therefore, results on the scales for personality, religious schemata, and well-being were presented with clear focus on the single cases, but also including the means for traditionalists and the two groups of deconverts, thus illustrating group differences and the individual trajectories they are based on. And obviously, the scores in the single cases of traditionalists and deconverts scatter widely in the twodimensional space, which will need to be discussed in the case studies. But also the position of and relation between the means of traditionalists and deconverts, as far as they are significant, yield some new insight in changes and stability between Time 1 and Time 2.

Lower agreeableness of Time 1 deconverts is a significant result, and that their lower scores on agreeableness also reveals as stable over time. But that every deconversion is associated with clearly lower agreeableness is not supported, because Time 2 deconverts are only slightly lower on agreeableness. It appears an open question whether this indicates a difference between Time 1 deconverts and Time 2 deconverts, or whether lower scores on agreeableness are rather independent from deconversion. Likewise, no strong conclusions can be drawn from the RSS subscale $t t t$. It is certainly an interesting finding that low scores on $t t t$ may have been stable over time for the Time 1 deconverts. But that, as assumed, deconversion is associated with lower $t t t$, 
is obviously not true for every deconvert, definitely not for Time 2 deconverts as a group. Ttt appears rather stable for both deconverts and traditionalists between both times of measurement. Taken together, personality factors, and here in particular agreeableness - the other personality factors were not significant in this deconversion revisited data-, and religious schemata, and here we attended in particular ttt, appear, on the basis of this sample of reinterviewees from the Deconversion Study, less strongly associated with deconversion than results from the first Deconversion Study suggested.

This is different for well-being: Here we see some dynamics of change that involves lower scores associated with deconversion, but also some recovery or improvement over the time distance of ten years. Between-group differences including changes over time, as presented in our scatter plots, were significant for purpose in life and self-acceptance only. But both have, among other well-being dimensions, revealed "signs of a loss or crisis" for the German deconverts in the first Deconversion Study. After the time of ten years, the current study could document higher scores on purpose in life and self-acceptance for these German Time 1 deconverts, and, at the same time, lower scores on purpose in life and self-acceptance for the Time 2 deconverts, who have deconverted in the more recent years. Thus, on purpose in life and self-acceptance, our results document a dynamics of crisis and recovery. It is very interesting to see this dynamic in the case studies. Then this chapter, with its attempt to quantitatively profile the sample of re-interviewees, would serve its aim and enrich the case studies that are presented in the chapters of this book.

\section{References}

Asendorpf, J. B., Borkenau, P., Ostendorf, F., \& Van Aken, M. a. G. (2001). Carving personality description at its joints: Confirmation of three replicable personality prototypes for both children and adults. European Journal of Personality, 15(3), 169198.

Costa, P. T., \& Mccrae, R. R. (1985). Revised NEO Personality Inventory (NEO PI-R) and NEO Five-Factor-Inventory (NEO-FFI). Professional manual. Odessa: Psychological Assessment Resources 1992.

Fowler, J. W. (1981). Stages of faith. The psychology of human development and the quest for meaning. San Francisco: Harper\&Row.

Fowler, J. W., Streib, H., \& Keller, B. (2004). Manual for fFaith Development Research (3rd ed.). Bielefeld; Atlanta: Research Center for Biographical Studies in Contemporary Religion, Bielefeld; Center for Research in Faith and Moral Development, Emory University. 
Gerlach, M., Farb, B., Revelle, W., \& Nunes Amaral, L. A. (2018). A robust data-driven approach identifies four personality types across four large data sets. Nature Human Behaviour, 2(10), 735-742.

Moseley, R. M., Jarvis, D., \& Fowler, J. W. (1986). Manual for Faith Development Research. Atlanta: Center for Faith Development, Emory University.

Paloutzian, R. F., Murken, S., Streib, H., \& Namini, S. (2013). Conversion, deconversion, and transformation: A multilevel interdisciplinary view. In R. F. Paloutzian \& C. L. Park (Eds.), Handbook of the psychology of religion and spirituality, 2nd ed. (pp. 399-421). New York: The Guilford Press.

Ryff, C. D. (1989). Happiness is everything, or is it? Explorations on the meaning of psychological well-being. Journal of Personality and Social Psychology, 57(6), 10691081.

Ryff, C. D., \& Singer, B. H. (1998). The role of purpose in life and growth in positive human health. In P. T. P. Wong \& P. S. Fry (Eds.), The human quest for meaning. Handbook of psychological research and clinical applications (pp. 213-235). Mahwah: Lawrence Erlbaum Associates.

Streib, H. (2001). Faith Development Theory revisited: The religious styles perspective. International Journal for the Psychology of Religion, 11(3), 143-158.

Streib, H. (2014). Deconversion. In L. R. Rambo \& C. E. Farhadian (Eds.), Oxford handbook on religious conversion (pp. 271-296). Oxford: Oxford University Press.

Streib, H., Chen, Z. J. \& Hood, R. W. (2019). Categorizing people by their preference for religious styles: Four types derived from evaluation of Faith Development Interviews, The International Journal for the Psychology of Religion, DOI: 10.1080/10508619.2019.1664213

Streib, H., \& Hood, R. W. (Eds.). (2016). Semantics and psychology of spirituality. A crosscultural analysis. Cham, Heidelberg, New York, Dordrecht, London: Springer International Publishing Switzerland.

Streib, H. (2018). What is Xenosophia? Philosophical Contributions to Prejudice Research. In H. Streib \& C. Klein (Eds.), Xenosophia and Religion: Biographical and Statistical Paths for a Culture of Welcome (pp. 3-21). Cham: Springer International Publishing Switzerland.

Streib, H., Hood, R. W., Keller, B., Csöff, R.-M., \& Silver, C. (2009). Deconversion. Qualitative and quantitative results from cross-cultural research in Germany and the United States of America. Göttingen: Vandenhoeck \& Ruprecht.

Streib, H., Hood, R. W., \& Klein, C. (2010). The Religious Schema Scale: Construction and initial validation of a quantitative measure for religious styles. International Journal for the Psychology of Religion, 20(3), 151-172.

Streib, H., \& Keller, B. (2004). The variety of deconversion experiences: Contours of a concept in respect to empirical research. Archive for the Psychology of Religion/Archiv für Religionspsychologie, 26(1), 181-200.

Streib, H., \& Keller, B. (2018). Manual for the Assessment of Religious Styles in Faith Development Interviews (Fourth, revised edition of the Manual for Faith Development Research). Bielefeld: Bielefeld University/readbox unipress. 